\title{
Overexpression of Matrix Metalloproteinases in Lung Tissue of Patients with Primary Spontaneous Pneumothorax
}

\author{
Chien-Kuang Chen ${ }^{a, b}$ Pin-Ru Chen ${ }^{b}$ Hsu-Chih Huang ${ }^{a, b}$ Yu-Sen Lin ${ }^{a, b}$ \\ Hsin-Yuan Fang ${ }^{\mathrm{a}-\mathrm{c}}$ \\ ${ }^{a}$ Graduate Institute of Clinical Medical Science, China Medical University, ${ }^{b}$ Division of Thoracic Surgery, Department \\ of Surgery, China Medical University Hospital, and 'School of Medicine, China Medical University, Taichung, Taiwan, \\ ROC
}

\section{Key Words}

Antiprotease · Gelatinase - Matrix metalloproteinase .

Primary spontaneous pneumothorax - Protease - Tissue inhibitors of metalloproteinase

\begin{abstract}
Background: Although blebs and bullae are frequently found in the apexes of lungs of patients with primary spontaneous pneumothorax (PSP), its pathogens remain unclear. Objectives: To examine the role of proteases [matrix metalloproteinase (MMP)-2, MMP-7 and MMP-9] and antiproteases [tissue inhibitors of metalloproteinase (TIMP)-1, TIMP-2, TIMP-3 and TIMP-4] in the pathogenesis of PSP. Method: Fifty consecutive PSP patients who received standard surgical care were enrolled in the study. Lung tissues from 20 patients with stage I non-small cell lung cancer were used as a control. Immunohistochemistry (IHC), reverse transcriptionpolymerase chain reaction (RT-PCR) and gelatin zymography were used to evaluate the expression of MMP and TIMP in the lung tissue of patients with PSP. Results: Overexpression of MMP-2, MMP-7 and MMP-9 was found in the afflicted lung by IHC, zymography and RT-PCR. By IHC, higher expression of MMP-2 and MMP-9 in PSP patients was identified in alveolar macrophages and type II pneumocytes (88 and $92 \%$ of
\end{abstract}

patients in macrophages, and 72 and $70 \%$ of patients in type II pneumocytes, respectively). MMP-2, MMP-7 and MMP-9 expression in patients was higher in mesothelial cells $(66,76$ and 76\%). Overexpression of TIMP-2 was detected in the extracellular matrix around bullae and blebs. Expression levels of TIMP-1, TIMP-3 and TIMP-4 were negligible ( $<10 \%$ of cells) in both PSP patients and controls. Conclusions: MMP-2, MMP-9, MMP-7 and TIMP-2 were upregulated in PSP lesions. These results suggest that an imbalance between the expression of proteases and antiproteases may be involved in the pathogeneses of PSP.

(c) 2014 S. Karger AG, Basel

\section{Introduction}

Three types of pneumothorax have been classified: traumatic, iatrogenic and spontaneous $[1,2]$. Primary spontaneous pneumothorax (PSP), which frequently occurs in persons without clinically evident lung disease, is most specific [3]. PSP patients are young (between 20 and 30 years) and slender, and the incidence rate is around $7.4-18$ cases per 100,000 men per year $[4,5]$. Pathologically, the ruptures are usually located in the vicinity of small bullae or a subpleural bleb in the lungs with normal

\section{KARGER}

E-Mail karger@karger.com www.karger.com/res
(C) 2014 S. Karger AG, Basel

0025-7931/14/0885-0418\$39.50/0
Dr. Hsin-Yuan Fang, MD, PhD

Division of Thoracic Surgery, Department of Surgery China Medical University Hospital, China Medical University

No. 2 Yude Road, Taichung 40447, Taiwan (ROC)

E-Mail d93421104@ntu.edu.tw 
appearance [6]. Although the mechanism of bulla formation remains to be determined, the presence of profuse neutrophils and macrophages, and sometimes partial tissue fibrosis, suggested that inflammation responses might have triggered aberrant changes in the afflicted regions, which in turn altered the delicate structures of elastic fibers in the lung $[7,8]$.

Elastic fibers, including collagens, elastin, fibronectin, laminins and proteoglycans, are major constituents of the basement membrane, a thin layer of specialized extracellular matrix (ECM) beneath pulmonary epithelium and alveoli. They not only provide structural support and spatial orientation for the overlying cells, but also regulate trafficking of macromolecules between cells [9]. Matrix metalloproteinases (MMPs) are a group of zinc- and calcium-dependent endopeptidases that can damage structural ECM components [10,11]. Based on the properties of their substrates, MMPs can be categorized into interstitial collagenases, stromelysins, gelatinases and membrane-type MMPs $[11,12]$. Excessive or inappropriate expression of MMPs, in particular MMP-2 and MMP-9, the two important members of type IV collagenase [10], could play a role in the pathogenesis of a variety of lung diseases [12-14], such as chronic obstructive pulmonary disease (COPD) and asthma, of which pathological evidence showed noticeable tissue damage and airway remodeling [15-18].

Tissue inhibitors of metalloproteinases (TIMPs) are low-molecular-weight proteins that can specifically inhibit activities of MMPs [19]. Four TIMPs (TIMP-1, TIMP-2, TIMP-3 and TIMP-4) have been characterized [20]. They are present in ECM and bind MMPs noncovalently in a 1:1 stoichiometric complex.

The role of MMP expression in PSP has yet to be determined. Although MMP-2 and MMP-9 are frequently reported in lung diseases, other MMPs and antiproteases have not been broadly investigated. In this study, we studied the expression of MMPs and TIMPs in pathological samples by immunohistochemistry (IHC). Gene expression was confirmed by reverse transcription-polymerase chain reaction (RT-PCR). Correlations between PSP and the expression of MMPs of various cell types were evaluated.

\section{Patients and Methods}

\section{Patients}

Between September 2003 and May 2004, 50 consecutive PSP patients who were admitted to the Department of General Thoracic Surgery, Changhua Christian Hospital (central Taiwan), and met our inclusion criteria were enrolled in this study. PSP was defined as spontaneous air accumulation in the pleural cavity without evidence of clinical lung disease. The inclusion criteria were: (1) pneumothorax noted by chest radiography on admission to the hospital and (2) patient age between 15 and 40 years. The exclusion criteria were: (1) a history of chest trauma, such as rib fracture and pulmonary contusion, and (2) a history of pulmonary surgery, including lobectomy, segmentectomy and wedge resection of the lung, (3) a history of one of the following lung diseases: COPD, asthma, pulmonary fibrosis, pulmonary tuberculosis, pneumonia or pneumoconiosis, and (4) a history of one of the following systemic diseases: end-stage renal failure, liver cirrhosis, malignancy, or chronic heart and liver diseases. In order to reduce the recurrence rate of PSP, we performed wedge resection of the suspected lesion site with mechanical pleurodesis by thoracoscopic surgery, and its central part was sampled for further study. All patients were followed for at least 1 year at the Outpatient Department. Nontumorous lung tissues from 20 sex-matched patients diagnosed as stage I non-small cell lung cancer (15-40 years old) were used as negative controls. The Ethics Committee of the Changhua Christian Hospital approved this protocol, and written informed consent was obtained from every patient before surgery. A single-blinded procedure was followed for IHC, RT-PCR and statistical analysis.

\section{Immunohistochemistry}

Expression of MMP-2, MMP-7, MMP-9, TIMP-1, TIMP-2, TIMP-3 and TIMP-4 in the pathological sections was assessed by an immunoperoxidase method as previously described [21, 22]. Briefly, paraffin blocks were sectioned at a thickness of $4 \mu \mathrm{m}$ for each case. The sections were deparaffinized in xylene, and xylene was subsequently removed with absolute ethanol. The slides were treated with $3 \% \mathrm{H}_{2} \mathrm{O}_{2}$ and $0.1 \%$ sodium azide to inactivate endogenous peroxidase before incubation with the respective antibodies to MMP-2, MMP-7, MMP-9 (Chemicon, Temecula, Calif., USA), TIMP-1, TIMP-2, TIMP-3 and TIMP-4 (Abcam, Cambridge, UK). The reaction was followed by biotin-conjugated goat anti-mouse immunoglobulin and horseradish peroxidase-conjugated streptavidin (DAKO, Glostrup, Denmark). Diaminobenzidine or aminoethyl carbazole was used as chromogenic substrate, and brown or crimson red precipitates were identified as positive staining. The slides were counterstained with hematoxylin and mounted with glycerol gelatin. In each experiment, a section of non-small cell lung cancer known to express MMPs served as a positive control, and a section without addition of the primary antibodies was used as a negative control. Each IHC batch contained a positive and a negative slide to ensure the quality of staining.

\section{Slide Evaluation}

Slide evaluation has been described previously [23, 24]. Each slide was evaluated randomly in four areas with obvious lesions. Photographs were taken at each evaluated area for records. Each slide was read and scored by two independent investigators. Staining intensity was scored semiquantitatively: -, with less than $10 \%$ of positive cells; +, weak staining, positive cells were between 10 and $50 \%$, and ++ , strong staining, with more than $50 \%$ of cells staining positive.

\section{Reverse Transcription-Polymerase Chain Reaction}

Following total RNA extraction and synthesis of the firststrand cDNA, an aliquot of cDNA was subjected to 35 cycles of 
PCR. The reaction mixture contained $1 \times$ Taq buffer (BRL, Bethesda, Md., USA), $1.5 \mathrm{mM} \mathrm{MgCl}_{2}, 2 \mu \mathrm{M}$ dNTP, $0.25 \mu \mathrm{M}$ of the respective $3^{\prime}$ and $5^{\prime}$ primers, 1 unit of Taq DNA polymerase and $2 \mu$ of cDNA. PCR was carried out in a standard procedure denaturing at $94^{\circ} \mathrm{C}$ for $30 \mathrm{~s}$, hybridizing at $52^{\circ} \mathrm{C}(\mathrm{MMP}-2) ; 55^{\circ} \mathrm{C}(\mathrm{MMP}-9) ; 51^{\circ} \mathrm{C}$ (MMP-7) and $53^{\circ} \mathrm{C}$ (MMP-12) for $30 \mathrm{~s}$, and elongating at $72^{\circ} \mathrm{C}$ for $1.2 \mathrm{~min}$. The primer sequences were selected by Primer3 (frodo. wi.mit.edu/cgi-bin/primer3).

- For MMP-2, the primer sequences were:

5'-TTGGTTTTGGCTGGCTTCTTCACT-3' (sense) $5^{\prime}$-CGCATTCTCGGTCACAGGAT-3' (antisense)

- For MMP-9, the primer sequences were:

5'-TGTGGGGAGGGGTTTGGGGAGGATA-3' (sense) 5'-TGAAAGGGAGGGAGGGGGATGAAGC-3' (antisense)

- For MMP-7, the primer sequences were: 5'-TGGCCTCACTTTCATTTTTGGTA-3' (sense) $5^{\prime}$-GGGCTGCATTGGTCCTTAGTA-3' (antisense)

- For MMP-12, the primer sequences were:

5'-GGCGAGGCTGACATTACGATACTT-3' (sense)

$5^{\prime}$-GAATACCGGGCCCAGGATAAAAA- $3^{\prime}$ (antisense).

The amplified DNA fragments were $115 \mathrm{bp}$ (MMP-2), $195 \mathrm{bp}$ (MMP-9), 116 bp (MMP-7) and 112 bp (MMP-12), respectively, as analyzed in a $2.5 \%$ agarose gel, and visualized by ethidium bromide staining. All RT-PCR data were normalized to the level of $\beta$-actin (286-bp) expression.

\section{Gelatin Gel Zymography}

Protein extracted from lung biopsies (300 mg) was loaded and separated on a $10 \%$ SDS-polyacrylamide gel with $0.1 \%$ gelatin substrate. Human MMP-2 and MMP-9 (Chemicon) were used as positive controls of gelatinase activity. The proenzyme of MMP-2 has a molecular weight of $72 \mathrm{kDa}$, and the mature form $64 \mathrm{kDa}$; the proenzyme of MMP-9 has a molecular weight of $92 \mathrm{kDa}$ and the active form $83 \mathrm{kDa}$. After separation, the gel was soaked in renaturing buffer containing 2.5\% Triton X-100 twice for $1 \mathrm{~h}$ each at room temperature with gentle agitation and then incubated with developing buffer (50 mM Tris- $\mathrm{HCl}, \mathrm{pH}$ 7.5, $200 \mathrm{~mm} \mathrm{NaCl}, 5 \mathrm{~mm}$ $\mathrm{CaCl}_{2}, 0.05 \%$ Brij-35 and $0.02 \% \mathrm{NaN}_{3}$ ). The gel was then stained with $0.5 \%$ Coomassie blue R-250 for $30 \mathrm{~min}$ and destained appropriately for densitometry analysis. Band intensity of zymographic gelatin among samples was estimated and normalized.

\section{Statistical Analysis}

Data are presented as means \pm SD. Quantitative data were analyzed by t test. Correlation of MMP expression with PSP was analyzed by either $\chi^{2}$ test or Fisher's exact test (when the expected number of cells analyzed was $\leq 5)$. Statistical analysis was performed using SPSS software (version 12.0; SPSS Inc., Chicago, Ill., USA). Statistical significance was set at $\mathrm{p}<0.05$.

\section{Results}

\section{Patient Characteristics}

The mean age of the PSP patients was $21.3 \pm 5.3$ years (range, 17-36 years). There were 48 males and 2 females. In the control group, the mean age was $35.4 \pm 5.2$ years (range, 25-40 years). Demographic data and operative
Table 1. Clinical characteristics of the PSP patients $(n=50)$

\begin{tabular}{lc}
\hline Age, years & $21.3 \pm 5.3$ \\
Male sex & $48(96 \%)$ \\
Height, cm & $173.0 \pm 6.8$ \\
Body weight, kg & $58.1 \pm 7.7$ \\
Smokers & $15(30 \%)$ \\
Side involved & \\
$\quad$ Right & $23(46 \%)$ \\
$\quad$ Left & $24(48 \%)$ \\
$\quad$ Bilateral & $3(6 \%)$ \\
Surgical indications & \\
$\quad$ Ipsilateral recurrence & $24(48 \%)$ \\
$\quad$ Persistent air leaks & $9(18 \%)$ \\
$\quad$ Contralateral recurrence & $4(8 \%)$ \\
$\quad$ Hemopneumothorax & $3(6 \%)$ \\
$\quad$ Other & $10(20 \%)$ \\
Presence of blebs & \\
$\quad$ Single bleb & $22(44 \%)$ \\
$\quad$ Double blebs & $5(10 \%)$ \\
$\quad$ Multiple blebs (>3) & $23(46 \%)$ \\
Time of operation, min & $85 \pm 35$ \\
Hospital stay, days & $6.4 \pm 1.9$
\end{tabular}

Data are presented as means \pm SD or numbers of cases (\%).

findings are shown in table 1. Surgical indications for PSP were ipsilateral recurrence (48\%), persistent air leakage $(18 \%)$, contralateral recurrence $(8 \%)$ and hemopneumothorax (6\%). The mean surgical time was $85 \pm 35 \mathrm{~min}$ and mean hospital stay was $6.4 \pm 1.9$ days. There was not any mortality or conversion as thoracoscopic surgery. Three patients $(6 \%)$ had air leak and were managed conservatively. Fifteen patients (30\%) were smokers, with a smoking duration and cigarette consumption of $5.5 \pm 2.5$ years and $1.2 \pm 0.3$ packages per day, respectively. All 50 PSP patients had bullae or blebs at the apex of the lung. In the control group, bullae were not detected.

\section{MMP-2, MMP-9 and MMP-7 Overexpression in Lung} Tissue of PSP Patients

Immunohistochemically, MMP-2, MMP-7 and MMP9 were overexpressed in PSP specimens (fig. 1). Differences in MMP expression between the PSP and control groups were highly significant. MMPs were mainly detected in alveolar macrophages and alveolar type II pneumocytes (table 2). MMPs were also detected in mesothelial cells and ECM. Interestingly, in some specimens, MMP-2 was detected in nuclei of mesothelial cells. Overexpression of MMP-2, MMP-7 and MMP-9 was also confirmed by RT-PCR (fig. 2), and mRNA in PSP tissue was clearly upregulated [MMP-2 (90\%), MMP-9 (80\%) and 
Fig. 1. Expression of MMP-2 in PSP detected by IHC staining. Representative examples of increased MMP-2 expression are shown in the upper row. a Bleb (original magnification $\times 100)$. b Alveolar type II pneumocytes (arrow, original magnification $\times 400$ ). c Alveolar macrophages (original magnification $\times 400)$. d Mesothelial cells (original magnification $\times 400$ ). Images in the lower row are negative controls.

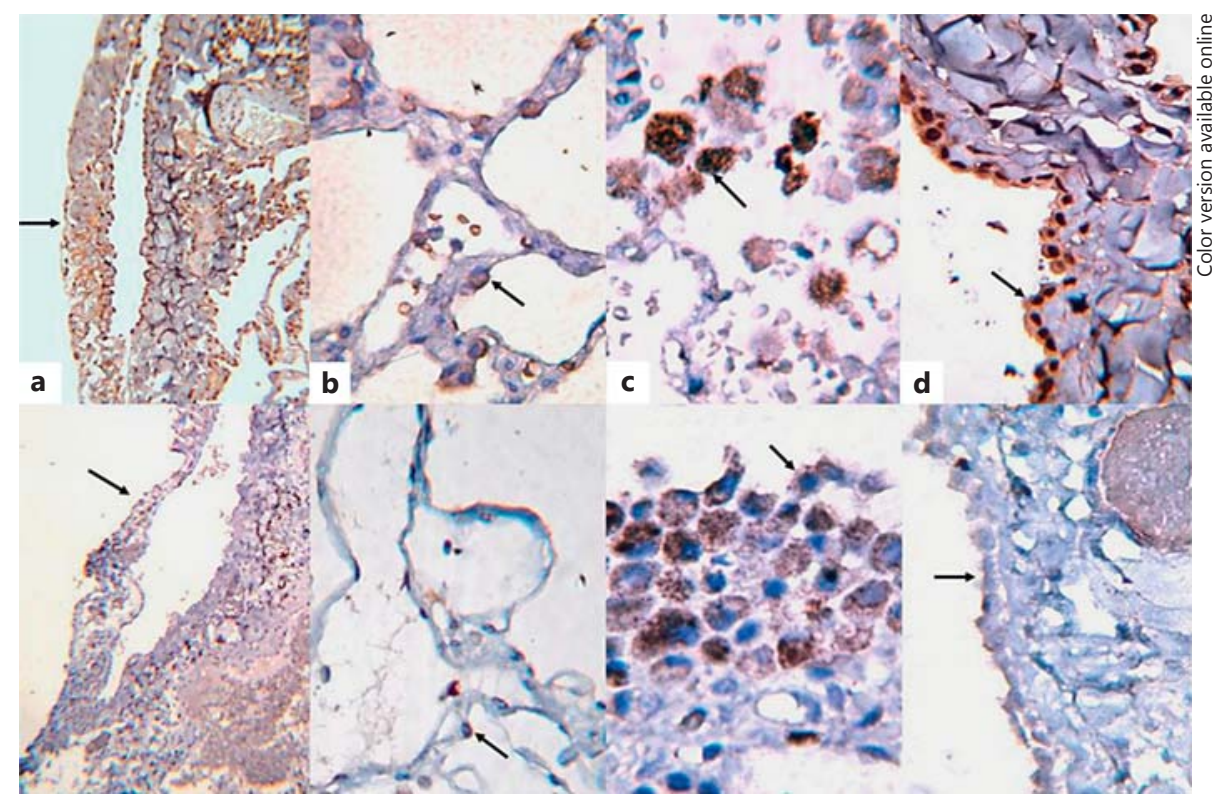

Table 2. Overexpression of MMP-2, MMP-9 and MMP-7 in PSP by IHC

\begin{tabular}{|c|c|c|c|c|c|}
\hline & \multicolumn{2}{|l|}{$\operatorname{PSP}(n=50)$} & \multicolumn{2}{|c|}{ Control $(n=20)$} & \multirow[t]{2}{*}{$\mathrm{p}$ value } \\
\hline & $++/+$ & - & $++/+$ & - & \\
\hline \multicolumn{6}{|l|}{ MMP-2 } \\
\hline Alveolar macrophages & $15 / 29(88 \%)$ & $6(12 \%)$ & $2 / 7(45 \%)$ & $11(55 \%)$ & $0.000^{*}$ \\
\hline Type I pneumocytes & $4 / 12(32 \%)$ & $34(67 \%)$ & $1 / 6(35 \%)$ & $13(65 \%)$ & 0.809 \\
\hline Type II pneumocytes & $8 / 27(70 \%)$ & $15(30 \%)$ & $2 / 6(40 \%)$ & $12(60 \%)$ & $0.020^{*}$ \\
\hline Mesothelial cells & $7 / 22(58 \%)$ & $21(42 \%)$ & $2 / 3(25 \%)$ & $15(75 \%)$ & $0.017^{*}$ \\
\hline ECM & $5 / 28(66 \%)$ & $17(34 \%)$ & $1 / 3(20 \%)$ & $16(80 \%)$ & $0.001^{*}$ \\
\hline \multicolumn{6}{|l|}{ MMP-9 } \\
\hline Alveolar macrophages & $33 / 13(92 \%)$ & $4(8 \%)$ & $3 / 6(45 \%)$ & $11(55 \%)$ & $0.000^{*}$ \\
\hline Type I pneumocytes & $2 / 21(46 \%)$ & $27(54 \%)$ & $2 / 6(40 \%)$ & $12(60 \%)$ & 0.604 \\
\hline Type II pneumocytes & $14 / 21(70 \%)$ & $15(30 \%)$ & $3 / 5(40 \%)$ & $12(60 \%)$ & $0.030^{*}$ \\
\hline Mesothelial cells & $10 / 28(76 \%)$ & $12(24 \%)$ & $3 / 3(30 \%)$ & $14(70 \%)$ & $0.001^{*}$ \\
\hline ECM & $7 / 23(60 \%)$ & $20(40 \%)$ & $2 / 3(25 \%)$ & $15(75 \%)$ & $0.016^{*}$ \\
\hline \multicolumn{6}{|l|}{ MMP-7 } \\
\hline Alveolar macrophages & $17 / 27(88 \%)$ & $6(12 \%)$ & $3 / 5(40 \%)$ & $12(60 \%)$ & $0.000^{*}$ \\
\hline Type I pneumocytes & $2 / 23(50 \%)$ & $25(50 \%)$ & $2 / 7(45 \%)$ & $11(55 \%)$ & 0.705 \\
\hline Type II pneumocytes & $11 / 19(60 \%)$ & $20(40 \%)$ & $4 / 6(50 \%)$ & $10(50 \%)$ & 0.445 \\
\hline Mesothelial cells & $9 / 29(76 \%)$ & $12(24 \%)$ & $2 / 3(25 \%)$ & $15(75 \%)$ & $0.000^{*}$ \\
\hline $\mathrm{ECM}$ & $7 / 13(40 \%)$ & $30(60 \%)$ & $1 / 3(20 \%)$ & $16(80 \%)$ & 0.111 \\
\hline
\end{tabular}

Categorical variables were analyzed by $\chi^{2}$ test and Fisher's exact test. ${ }^{*} \mathrm{p}<0.05 .-=$ Negative; $+=$ low expression; $++=$ high expression. 


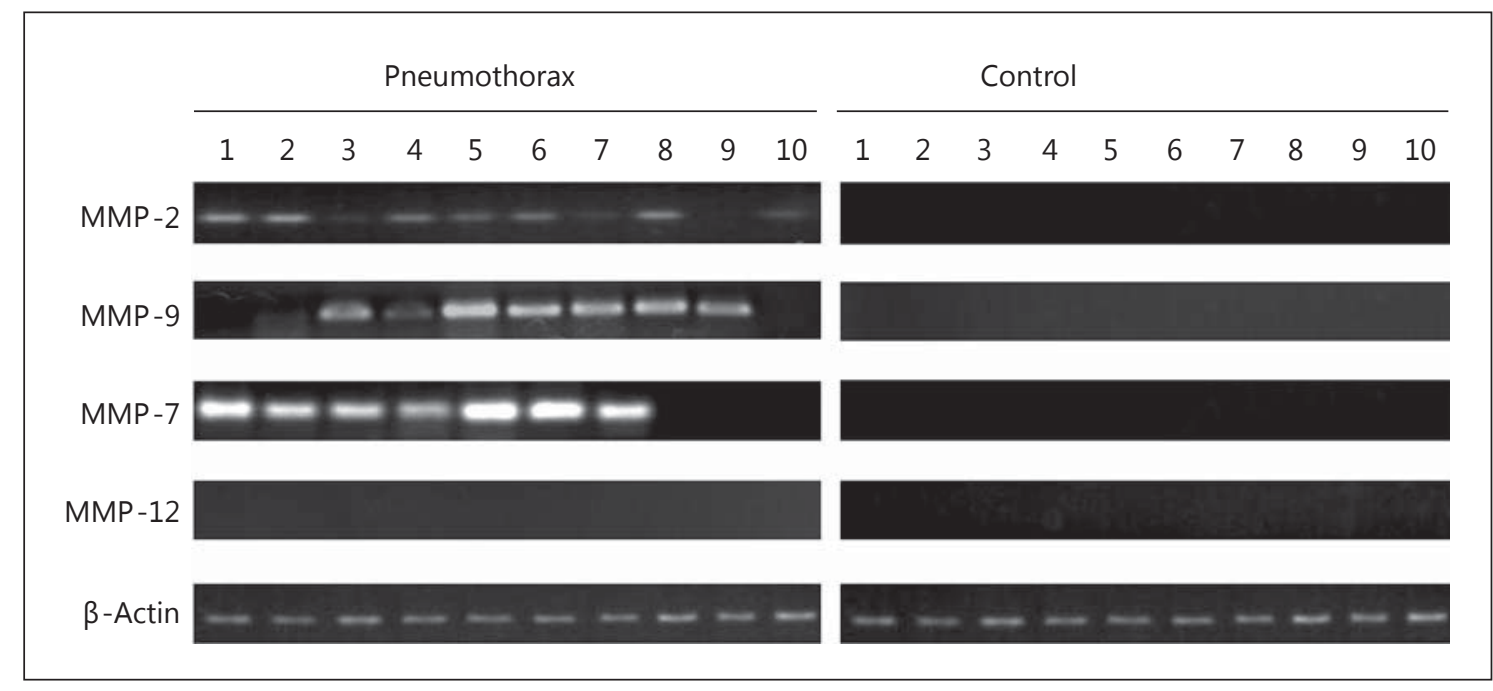

Fig. 2. Overexpression of MMPs in PSP specimens was confirmed by RT-PCR.

MMP-7 (70\%)]. However, mRNA of MMP-12 was not markedly increased.

Expression of TIMP-1, TIMP-2, TIMP-3 and TIMP-4 in Lung Tissue of PSP Patients

IHC expression of TIMP-1, TIMP-3 and TIMP-4 was negligible $(<10 \%)$ in both PSP and control specimens. Interestingly, expression of TIMP-2 was much higher (75\%) in the diseased lung than in the control tissue, and the difference was significant $(\mathrm{p}<0.001)$. TIMP-2 expression was not detected in alveolar macrophages, or type I or II pneumocytes, but in the ECM around bullae and blebs (fig. 3).

Increased Enzyme Levels and Activity of MMP-2 and MMP-9 in PSP Samples

By zymography, 6 biopsy samples, in which MMP-2 overexpression was determined by RT-PCR, showed markedly increased enzyme levels of pro-MMP-2, active MMP-2 and active MMP-9 (fig. 4). In the control group, although some pro-MMP was detected, active MMP was not identified.

\section{Discussion}

The etiology of PSP is a subject of discussion. PSP is defined as spontaneous pneumothorax which is not associated with lung disease, which implies that there are no pathological changes in the lung tissue. Emphysema-like

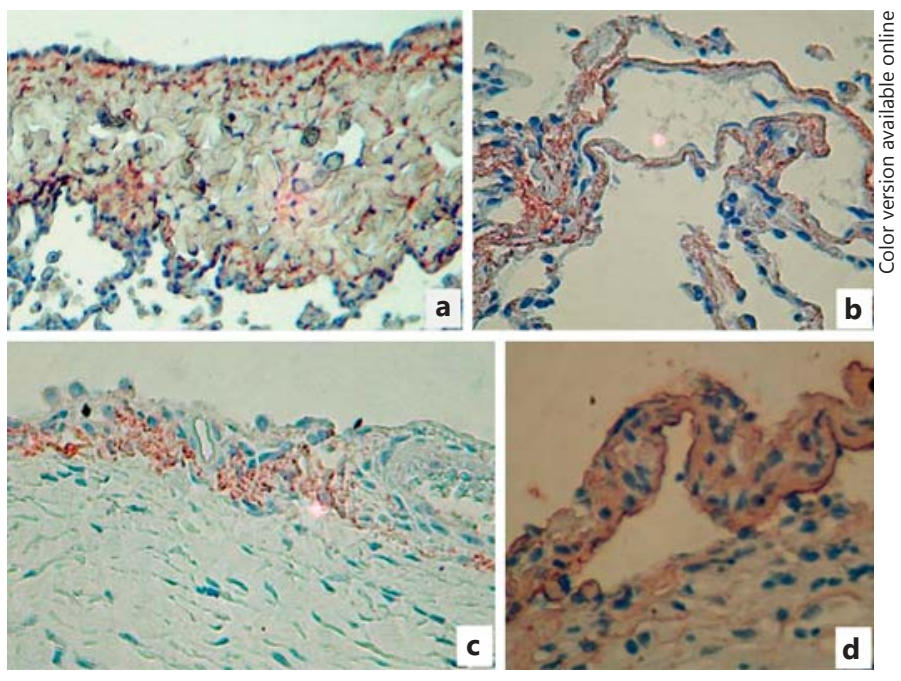

Fig. 3. Expression of TIMP-2 in PSP detected by IHC staining. Representative examples of increased TIMP-2 expression. a Visceral pleural thickness near the bullae (original magnification $\times 200$ ). $\mathbf{b}$ ECM at the alveolar sac (original magnification $\times 200$ ). c Subpleural matrix (arrows, original magnification $\times 200$ ). d Bleb (original magnification $\times 400$ ).

changes were easily found in patients with PSP [25]. Pleural porosity was also found and considered to be related to PSP etiology [26]. Behavior and environment may be risk factors for developing spontaneous pneumothorax, such as smoking and air pollution [27, 28]. Smoking is also well known to be associated with the development of 


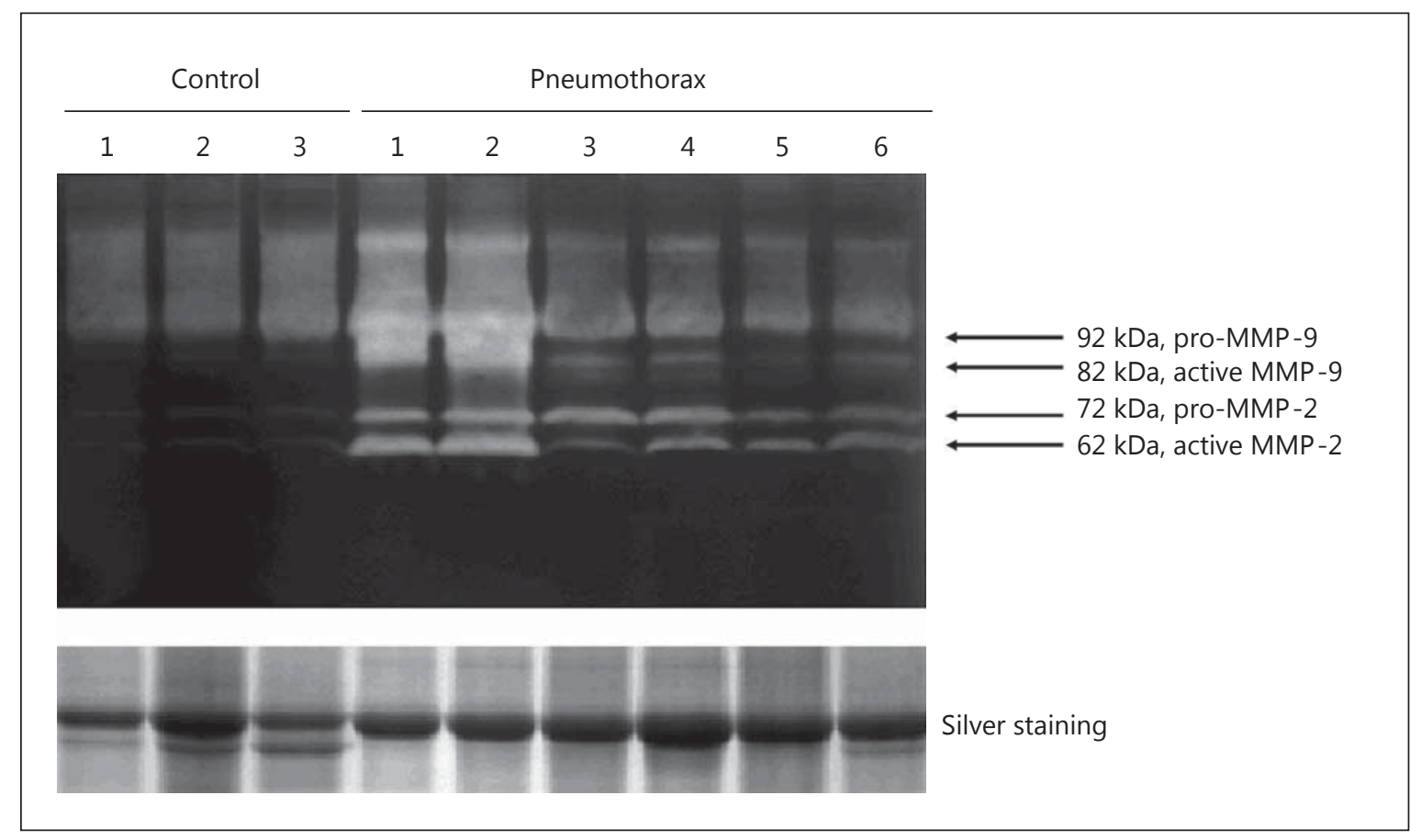

Fig. 4. Type and activity of MMP determined by zymographic gel analysis. Silver staining shows the loaded proteins.

COPD. The pathological changes in the lung possibly develop in peripheral airways of young smokers before COPD symptoms establish [29]. MMP-2 and MMP-9 levels were elevated in the sputum and bronchoscopy lavage fluid of patients with COPD and emphysema [10].

We observed MMP-2, MMP-7, MMP-9 and TIMP-2 overexpression in PSP lesions. MMPs were overexpressed in alveolar macrophages and alveolar type II epithelial cells, the two major cell types that are essential for removing injured tissue and reconstructing the intact alveolus. On the other hand, TIMP-2 was expressed in ECM around the PSP lesion sites. As noted previously, MMPs belong to a family of proteolytic enzymes that have multiple important physiological roles, such as ECM remodeling, cleavage activation of cytokines, facilitation of cell migration and activation of defensins [12, 23, 30-32]. MMP function was evaluated by MMP knockout. MMP2-knockout mice show decreased angiogenesis and tumor growth. In MMP-7-knockout mice, repair of mucosal epithelium wounds of the lung was impaired, and MMP-9-knockout mice lacked alveolar bronchiolization [33]. These results suggest associations between MMP-2, MMP-7 and MMP-9 overexpression in PSP tissue and tissue repair and remodeling.

Expression of MMPs in PSP
Under normal conditions, MMP-2 is produced and secreted by endothelium and macrophages [34], and MMP9 is produced and secreted by neutrophils and eosinophils $[35,36]$. Under inflammatory conditions, MMP-9 was also found in macrophages and alveolar cells [10]. In our study, overexpression of MMP-9 was observed in macrophages and type II pneumocytes, indicating an inflammatory condition. Possibly, inflammation of the lung resulted in increased MMP-2 and MMP-9 expression, inducing lung remodeling and the development of emphysema-like changes.

Smoking seems to be important for PSP development, but smoking rate was low in our patients. Therefore, there might be some other driving factor for PSP such as air pollution. In our previous study, using DNA microarrays to study gene expression in PSP, a relationship with inflammation, hypoxemia and apoptosis was found [37]. Associations between MMP-7 overexpression and apoptosis and angiogenesis were also reported [38]. Nuclear MMP-2 was found in cardiac myocytes after ischemia and reperfusion. Nuclear localization of MMP-2 in the thickened mesothelial cells was also observed. Muscular hypertrophy, arterial remodeling and endothelial dysfunction following inflammation and hypoxia were also noted in COPD pathogenesis [39], which may be ex- 
plained by chronic hypoxic stress $[33,40]$ and tissue repair as well as remodeling of the diseased area, for example [41].

Chronic hypoxia might then provoke inflammatory reactions, activate macrophages in the damaged area to secrete gelatinases to initiate tissue remodeling and finally induce a vicious cycle. The cell density of alveolar macrophages in PSP patients and the higher MMP-2 and MMP-9 levels in alveolar macrophages from PSP patients supported the anticipated scheme of tissue responses. Increases in macrophage-associated elastolytic activities and elastin degradation in combination with the increased air pressure in the pulmonary alveolar space could lead the reconstructing alveolus to grow toward the pleural cavity and form blebs and bulla on the mesothelial surface of the lung.

Nevertheless, our findings of MMP overexpression in PSP indicated that PSP may result from tissue repair and lung remodeling possibly induced by inflammation and local hypoxia. It is clear though that MMP expression can be directly or indirectly associated with the severity of inflammation, hypoxia and tissue damage, and this in and of itself should provide an interesting target for discovering and designing an early scheme for disease prevention.

However, this study has some limitations. Due to moral issues, tissue of the healthy part of the lung was not available from PSP patients, which would serve as the ide- al negative control. We used non-tumorous lung tissue from patients with stage I lung cancer as a negative control, which might introduce some bias. Because we only got lesion sites, we could not determine if the findings were localized or generalized. The current study included only a selected collection of PSP patients who required immediate surgical management owing to ipsilateral or contralateral recurrence, persistent air leakage or hemopneumothorax. These results might not be generalizable to all PSP patients, in particular those who did not receive surgical management. A more extensive and detailed study is required.

\section{Conclusions}

In this study, we showed that MMP-2, MMP-9, MMP7 and TIMP-2 were upregulated in PSP lesions. Our data suggest that an imbalance between protease and antiprotease expression may play a role in PSP development.

\section{Financial Disclosure and Conflicts of Interest}

None of the authors had financial and personal relationships with other people or organizations that could inappropriately influence this work.

\section{References}

1 Baumann MH, Noppen M: Pneumothorax. Respirology 2004;9:157-164.

2 Van Schil P, de Vos B: Current treatment of primary and secondary pneumothorax. Rev Mal Respir 2004;21:372-380.

-3 Noppen M: Management of primary spontaneous pneumothorax. Curr Opin Pulm Med 2003;9:272-275.

4 Melton LJ, Hepper NGG, Offord KP: Incidence of spontaneous pneumothorax in Olmsted County, Minnesota - 1950 to 1974. Am Rev Respir Dis 1979;120:1379-1382.

5 Morimoto T, Shimbo T, Noguchi Y, Koyama H, Sasaki Y, Nishiwaki K, Fukui T: Effects of timing of thoracoscopic surgery for primary spontaneous pneumothorax on prognosis and costs. Am J Surg 2004;187:767-774.

-6 Ayed AK: Suction versus water seal after thoracoscopy for primary spontaneous pneumothorax: prospective randomized study. Ann Thorac Surg 2003;75:1593-1596.

-7 Sahn SA, Heffner JE: Spontaneous pneumothorax. N Engl J Med 2000;342:868-874.
8 Haraguchi S, Fukuda Y: Histogenesis of abnormal elastic fibers in blebs and bullae of patients with spontaneous pneumothorax: ultrastructural and immunohistochemical studies. Acta Pathol Jpn 1993;43:709-722.

9 Mattos W, Lim S, Russell R, Jatakanon A, Chung F, Barnes PJ: Matrix metalloproteinase- 9 expression in asthma - effect of asthma severity, allergen challenge, and inhaled corticosteroids. Chest 2002;122:1543-1552.

10 Chakrabarti S, Patel KD: Matrix metalloproteinase-2 (MMP-2) and MMP-9 in pulmonary pathology. Exp Lung Res 2005;31:599621.

$D_{11 \mathrm{Vu}} \mathrm{TH}, \mathrm{Werb} \mathrm{Z}$ : Matrix metalloproteinases: effectors of development and normal physiology. Genes Dev 2000;14:2123-2133.

12 Ohbayashi H: Matrix metalloproteinases in lung diseases (review). Curr Protein Pept Sci 2002;3:409-421.

13 Pardo A, Selman M: Matrix metalloproteinases and lung injury. Braz J Med Biol Res 1996;29:1109-1115.
14 Perez-Ramos J, Segura-Valdez MD, Vanda B, Selman M, Pardo A: Matrix metalloproteinases 2,9 , and 13 , and tissue inhibitors of metalloproteinases 1 and 2 in experimental lung silicosis. Am J Respir Crit Care 1999;160: 1274-1282.

-15 Sweet DG, Curley AE, Chesshyre E, Pizzotti J, Wilbourn MS, Halliday HL, Warner JA: The role of matrix metalloproteinases- 9 and -2 in development of neonatal chronic lung disease. Acta Paediatr 2004;93:791-796.

-16 Montano M, Beccerril C, Ruiz V, Ramos C, Sansores RH, Gonzalez-Avila G: Matrix metalloproteinases activity in COPD associated with wood smoke. Chest 2004;125:466-472.

17 Suzuki R, Miyazaki Y, Takagi K, Torii K, Taniguchi H: Matrix metalloproteinases in the pathogenesis of asthma and COPD: implications for therapy. Treat Respir Med 2004;3: 17-27.

18 Belvisi MG, Bottomley KM: The role of matrix metalloproteinases (MMPs) in the pathophysiology of chronic obstructive pulmonary disease (COPD): a therapeutic role for inhibitors of MMPs? Inflamm Res 2003;52:95-100. 
19 Giarnieri E, Alderisio M, Mancini R, Falasca C, Ricci A, Mariotta S, Giovagnoli MR: Tissue inhibitor of metalloproteinase 2 (TIMP-2) expression in adenocarcinoma pleural effusions. Oncol Rep 2008;19:483-487.

20 Denhardt DT, Feng B, Edwards DR, Cocuzzi ET, Malyankar UM: Tissue inhibitor of metalloproteinases (TIMP, aka EPA): structure, control of expression and biological functions. Pharmacol Ther 1993;59:329-341.

-21 Sahn SA, Heffner JE: Spontaneous pneumothorax. N Engl J Med 2000;342:868-874.

$\checkmark 22$ Cataldo D, Munaut C, Noel A, Frankenne F, Bartsch P, Foidart JM, Louis R: Matrix metalloproteinases and TIMP-1 production by peripheral blood granulocytes from COPD patients and asthmatics. Allergy 2001;56:145151.

23 Matsui K, Takeda K, Yu ZX, Travis WD, Moss J, Ferrans VJ: Role for activation of matrix metalloproteinases in the pathogenesis of pulmonary lymphangioleiomyomatosis. Arch Pathol Lab Med 2000;124:267-275.

-24 Yao PM, Buhler JM, d’Ortho MP, Lebargy F, Delclaux C, Harf A, Lafuma C: Expression of matrix metalloproteinase gelatinases $\mathrm{A}$ and $\mathrm{B}$ by cultured epithelial cells from human bronchial explants. J Biol Chem 1996;271:1558015589.

25 Grundy S, Bentley A, Tschopp JM: Primary spontaneous pneumothorax: a diffuse disease of the pleura. Respiration 2012;83:185-189.

-26 Haynes D, Baumann MH: Pleural controversy: aetiology of pneumothorax. Respirology 2011;16:604-610
27 Cheng YL, Huang TW, Lin CK, Lee SC, Tzao $\mathrm{C}$, Chen JC, Chang H: The impact of smoking in primary spontaneous pneumothorax. J Thorac Cardiovasc Surg 2009;138:192-195.

-28 Bertolaccini L, Alemanno L, Rocco G, Cassardo C: Air pollution, weather variations and primary spontaneous pneumothorax. J Thorac Dis 2010;2:9-15.

29 Niewoehner DE, Kleinerman J, Rice DB: Pathologic changes in the peripheral airways of young cigarette smokers. N Engl J Med 1974;291:755-758.

30 Elkington PT, Friedland JS: Matrix metalloproteinases in destructive pulmonary pathology. Thorax 2006;61:259-266.

31 Hayashi T, Rush WL, Travis WD, Liotta LA, Stetler-Stevenson WG, Ferrans VJ: Immunohistochemical study of matrix metalloproteinases and their tissue inhibitors in pulmonary Langerhans' cell granulomatosis. Arch Pathol Lab Med 1997;121:930-937.

32 Sukura A, Konttinen YT, Sepper R, Kaartinen L, Sorsa T, Lindberg LA: Collagenases and the serine proteinases elastase and cathepsin $\mathrm{G}$ in steroid-induced Pneumocystis carinii pneumonia. J Clin Microbiol 1995;33:829-834.

33 Parks WC, Shapiro SD: Matrix metalloproteinases in lung biology. Respir Res 2001;2: 10-19.

34 Frisch SM, Morisaki JH: Positive and negative transcriptional elements of the human type IV collagenase gene. Mol Cell Biol 1990;10: 6524-6532.
35 Devarajan P, Johnston JJ, Ginsberg SS, Van Wart HE, Berliner N: Structure and expression of neutrophil gelatinase cDNA. Identity with type IV collagenase from HT1080 cells. J Biol Chem 1992;267:25228-25232.

36 Schwingshackl A, Duszyk M, Brown N, Moqbel R: Human eosinophils release matrix metalloproteinase- 9 on stimulation with TNFalpha. J Allergy Clin Immunol 1999;104:983989.

37 Fang HY, Lin CY, Chow KC, Huang HC, Ko WJ: Microarray detection of gene overexpression in primary spontaneous pneumothorax. Exp Lung Res 2010;36:323-330.

38 Ii M, Yamamoto H, Adachi Y, Maruyama Y, Shinomura Y: Role of matrix metalloproteinase-7 (matrilysin) in human cancer invasion, apoptosis, growth, and angiogenesis. Exp Biol Med (Maywood) 2006;231:20-27.

-39 Turato G, Zuin R, Saetta M: Pathogenesis and pathology of COPD. Respiration 2001;68: 117-128.

40 Kwan JA, Schulze CJ, Wang WJ, Leon H, Sariahmetoglu M, Sung M, Sawicka J, Sims DE, Sawicki G, Schulz R: Matrix metalloproteinase-2 (MMP-2) is present in the nucleus of cardiac myocytes and is capable of cleaving poly (ADP-ribose) polymerase (PARP) in vitro. FASEB J 2004; 18:690-692.

41 Mercer BA, Kolesnikova N, Sonett J, D’Armiento J: Extracellular regulated kinase/ mitogen activated protein kinase is up-regulated in pulmonary emphysema and mediates matrix metalloproteinase- 1 induction by cigarette smoke. J Biol Chem 2004;279:1769017696. 